\title{
FIBRA DE PET NA PRODUÇÃO DE CONCRETOS
}

\author{
Nara Caroline da Silva Rodrigues ' \\ Magnny Maisy de Barros Carvalho ' \\ Anna Victoria Morais Balbino' \\ Adriano Luiz Roma Vasconcelos '
}

\section{Resumo}

O impacto sociambiental provocado pela impulsiva geração de resíduos orgânicos e inorgânicos sem destinação adequada é alarmante no presente. Frente a esta realidade, o uso da fibra de Polietileno Tereftalato (PET) incorporada ao concreto representa, portanto, uma escolha de grande valia. Trata-se de uma alternativa sustentável que engloba destino à grande quantidade de PET descartado no meio ambiente e, também, aperfeiçoamento das propriedades da matriz cimentícea do concreto convencional. $O$ objetivo desta pesquisa foi avaliar o desempenho mecânico do concreto sem adição das fibras poliméricas em detrimento do compósito. Realizou-se a confecção de 40 corpos de prova nos teores de $0 \%, 4,5 \%, 5 \%$ e 5,5\% de fibras de garrafa PET. Estes concretos foram avaliados através dos ensaios de resistência à compressão axial e à tração por compressão diametral aos 28 dias. Os resultados mostraram que esta adição não garante grande ganho de resistência à compressão, em contrapartida, minimiza o comportamento frágil do concreto convencional, tal como o aumento, mesmo que pouco significativo, da capacidade de deformação. Devido a isso, sua viabilidade de aplicação é garantida.

Palavras-chave: Fibra polimérica; PET; Concreto sustentável; Desempenho mecânico.

\section{PET FIBER IN CONCRETE PRODUCTION}

\begin{abstract}
The socio-environmental impact caused by the impulsive generation of organic and inorganic waste without adequate disposal is alarming in the present. In view of this reality, the use of Polyethylene Terephthalate (PET) fiber incorporated in the concrete represents, therefore, a choice of great value. It is a sustainable alternative that encompasses destiny to the large amount of PET discarded in the environment and, also, improvement of the properties of the cementitious matrix of conventional concrete. The objective of this research was to evaluate the mechanical performance of the concrete without adding the polymer fibers to the detriment of the composite. The preparation of 40 specimens in the contents of $0 \%$, $4.5 \%, 5 \%$ and $5.5 \%$ of PET bottle fibers was carried out. These concretes were evaluated by tests of axial compression strength and diametral compression traction at 28 days. The results showed that this addition does not guarantee a great gain of compressive strength, in contrast, it minimizes the brittle behavior of conventional concrete, such as the increase, even if not significant, in the tensile strength. Due to this, its viability of application is guaranteed.
\end{abstract}

Keywords: Polymeric fiber; PET; Sustainable concrete; Mechanical performance.

\section{INTRODUÇÃo}

O crescente consumismo, além de manter o fluxo de capitais, garante a geração de riqueza. Por outro lado, na perspectiva ambiental, o consumo exacerbado resulta em degradação ambiental, promovida, sobretudo, pela necessidade de constante exploração dos recursos naturais, o que influencia no aumento da produção de poluição e resíduos. Vários estudos concluem que o conceito de sustentabilidade é formado por três dimensões que se conectam: econômica, ambiental e social [I].

Nessa perspectiva, se faz necessário aliar a sustentabilidade ao desenvolvimento de forma harmônica. O caminho da sustentabilidade deve ser guiado com ações pontuadas com planejamento e avaliações. Na tentativa de minimizar desperdícios e dar reaproveitamento aos materiais,

'Centro Universitário Tocantinense Presidente Antônio Carlos, Araguaína, TO, Brasil.E-mail: naracarol_@hotmail.com

*Versão revisada de trabalho apresentado na ABM Week 2017, de 2 a 6 de outubro de 2017, São Paulo, SP, Brasil.

2176-1523 (c) 2017 Associação Brasileira de Metalurgia, Materiais e Mineração. Publicado pela ABM. Este é um artigo de acesso aberto distribuído sob os termos da licença Creative Commons CC BY-NC-ND (Attribution-NonCommercial-NoDerivs) - https:// creativecommons.org/licenses/by-nc-nd/4.0/. 
adicionar fibras ao concreto, surge como uma alternativa para tal realidade. Contudo a inserção de fibras na matriz do compósito não está ligada somente na minimização dos resíduos, mas também no de agregar novas propriedades ao concreto além de aprimorar as características já existentes.

Segundo Galvão [2], o concreto não armado é um material frágil, quebradiço e possui baixa resistência aos esforços de tração. Ao adicionar fibras, mesmo que descontínuas e aleatórias ao concreto, tende-se a ter uma melhoria na resistência do mesmo, atuando nas fissuras que ocorreram devido a exposição de umidade ou mudanças de temperatura do meio ambiente.

Contudo, inúmeras pesquisas vêm sendo impulsionadas no intuito de unir o desenvolvimento construtivo à sustentabilidade, tendo em vista o grande impacto que $\circ$ meio da construção civil também tem acarretado.

\section{MATERIAIS E MÉTODOS}

\section{I Obtenção e Corte das Fibras de PET}

As garrafas de PET utilizadas na pesquisa seriam destinadas ao descarte, contudo foram recolhidas e passaram pelo processo de lavagem e secagem. Para a obtenção das fibras aproveitou-se a área útil, por ser mais maleável, como demonstrado na Figura Ia. Descartou-se as demais áreas e após o corte com tesoura encaminhou o material para o filetador manual, como na Figura Ib. No filetador foram efetuados cortes horizontais na espessura de $5 \mathrm{~mm}$. Conseguinte, o corte para a obtenção do comprimento foi realizado manualmente. A fibra, portanto, assume a seguinte geometria: $10 \mathrm{~cm}$ de comprimento e $05 \mathrm{~mm}$ de largura, como ilustrado na Figura Ic.

O ensaio de massa unitária foi realizado visando conhecer melhor as características desse material. Esse ensaio consistiu na presença de um recipiente de volume conhecido e uma quantidade qualquer de massa de PET, que foi posteriormente pesada. O cálculo de massa unitária é representado como sendo a razão da massa de fibras pelo volume do recipiente (Equação I), seus dados foram especificados na Tabela I. De posse dessa informação, calculou-se a quantidade de fibras de acordo com o conhecimento do volume do molde do corpo de prova utilizado para confecção do concreto.

$$
\gamma_{\left(\frac{\mathrm{kg}}{\mathrm{m}^{3}}\right)}=\frac{M_{\text {fibras }(\mathrm{kg})}}{V_{\text {recipiente }\left(\mathrm{m}^{3}\right)}}
$$

\subsection{Caracterização dos Agregados}

A caracterização granulométrica dos agregados foi realizada por meio do ensaio de granulometria que segue os procedimentos da NBR 7217 [3]. Através deste ensaio foi possível obter o módulo de finura do agregado miúdo e diâmetro máximo do agregado graúdo, como demonstrados na tabela 2. Esses dados foram essenciais para a confecção do traço.

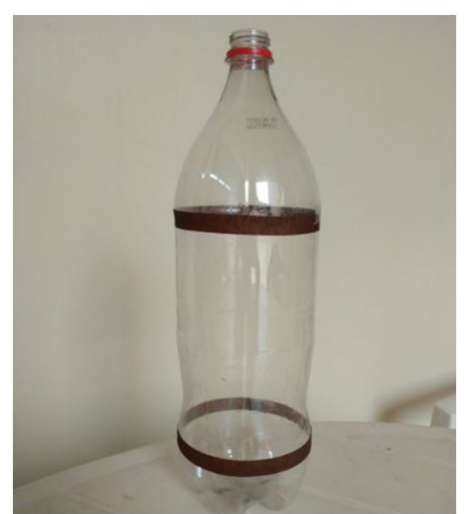

a. Aproveitamento da Garrafa PET

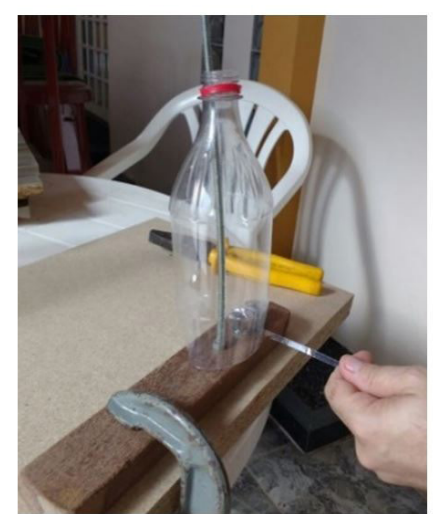

b. Corte da garrafa PET com auxílio do filetador.

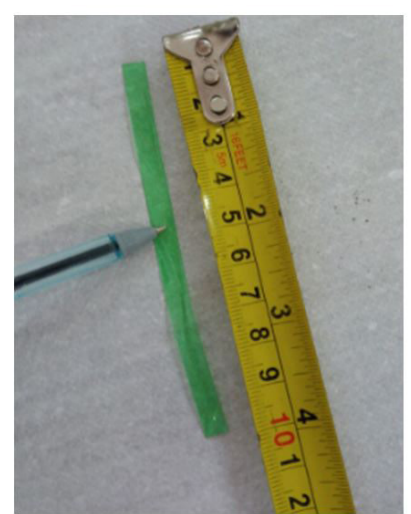

c. Fibra de PET medida com auxílio da trena.

Figura I. Corte das fibras de PET.

Tabela I. Massa específica do PET

\begin{tabular}{lccc}
\hline \multicolumn{1}{c}{ Tipo } & Volume inicial $\left(\mathbf{m}^{3}\right)$ & Massa do Agregado $(\mathbf{K g})$ & Peso Específico $\left(\mathbf{K g} / \mathbf{m}^{3}\right)$ \\
\hline Amostra 01 & $0,00 I 57$ & 0,07 & 44,586 \\
Amostra 02 & $0,00 I 57$ & 0,09 & 57,325 \\
Amostra 03 & $0,00 I 57$ & 0,12 & 76,433 \\
Peso específico médio $\left(\mathrm{Kg} / \mathrm{m}^{3}\right)$ & & & 59,448 \\
\hline
\end{tabular}

Fonte: Autor (20I7). 
Tabela 2. Dimensões dos Agregados

\begin{tabular}{lcc}
\hline & Agregado Miúdo & Agregado Graúdo \\
\hline Módulo de finura & $\mathrm{I}, 99$ & - \\
Diâmetro Máximo & - & 12,5 \\
\hline
\end{tabular}

Outros ensaios realizados para contribuir na caracterização dos agregados foram a massa específica e a massa unitária dos mesmos. A massa específica encontrada do agregado miúdo foi de $2670 \mathrm{Kg} / \mathrm{m}^{3}$, enquanto a do agregado graúdo foi de $2810 \mathrm{Kg} / \mathrm{m}^{3}$, o ensaio foi realizado conforme a NBR 9776 [4]. Com respaldo na NBR NM 45 [5], o valor encontrado para massa unitária do agregado miúdo foi de $1665,83 \mathrm{Kg} / \mathrm{m}^{3}$, ao passo que a do agregado graúdo aferiu-se $1772,50 \mathrm{Kg} / \mathrm{m}^{3}$.

\subsection{Preparação dos Corpos de Prova}

O traço utilizado foi de I: I, 12: 2, I7 a/c 0,39 e abatimento estipulado em $70 \pm 20$, calculado através do método $A B C P$, sendo que a adição de PET foi definida através da porcentagem em relação ao volume do molde do corpo de prova. Foram confeccionados 40 corpos de prova divididos proporcionalmente em PET 0, PET I, PET 2 e PET 3, contendo $0 \%, 4,5 \%, 5 \%$ e $5,5 \%$ respectivamente.

A moldagem foi realizada de acordo com a NBR 5738 [6], o molde utilizado tem o formato cilíndrico e possui dimensão de $0,10 \times 0,20 \mathrm{~m}$, foi também respeitado a temperatura e umidade para o processo de cura, que teve duração de 28 dias.

\section{RESULTADOS E DISCUSSÃO}

Os corpos de prova foram submetidos a ensaios de tração por compressão diametral e compressão axial, todos eles foram submetidos a cargas constantes até o momento de sua ruptura, estando ambos de acordo com as normas vigentes para cada ensaio.

\section{I Ensaio de Compressão Axial}

Para este ensaio utilizou-se a prensa hidráulica EMIC 23-200, do laboratório de Materiais de Construção do Centro Universitário ITPAC. Os corpos de prova foram submetidos a cargas constantes e após o rompimento utilizou-se da carga máxima aplicada para calcular o valor da tensão de compressão axial (Equação 2), de acordo com a NBR 5739 [7].

$$
F c=\frac{4 x F}{\pi x D^{2}}
$$

Onde: Fc é a resistência à compressão, em MPa; $F$ é a força máxima alcançada, em $\mathrm{N}$ e $\mathrm{D}$ é o diâmetro do corpo de prova, em $\mathrm{mm}$.
Tabela 3. Resultados do Ensaio de Compressão Axial

\begin{tabular}{lrrrr}
\hline & PET 0 & PET I & PET 2 & PET 3 \\
\hline Média (MPa) & 25,14 & 20,72 & 20,69 & 20,75 \\
Desvio Padrão(MPa) & 0,57 & 0,46 & 0,54 & 0,35 \\
Coef. de variação(\%) & 0,023 & 0,022 & 0,026 & 0,017 \\
\hline
\end{tabular}

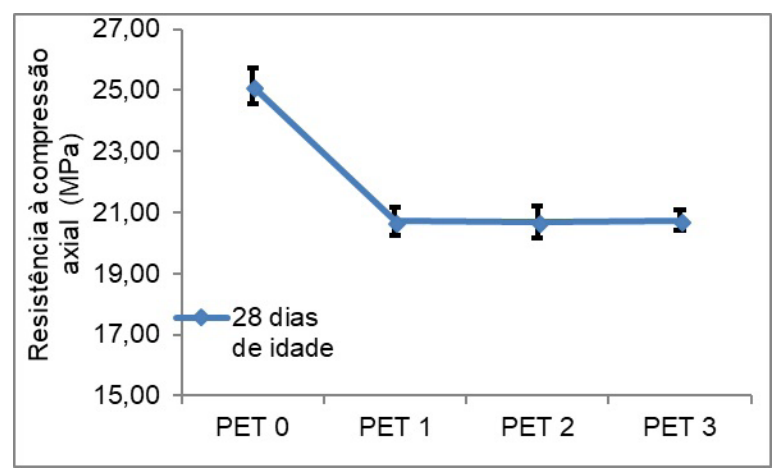

Figura 2. Resistência à compressão axial.

Através da fórmula, foi possível calcular a resistência característica para cada dosagem de fibra de PET, inclusive para o concreto sem a fibra de PET. Os valores podem ser analisados conforme a Tabela 3.

A adição de fibras proporcionou um decréscimo no valor da resistência à compressão, como pode ser melhor analisado na Figura 2. Mesmo com a ocorrência desta queda considerável do desempenho mecânico nos corpos de prova que continham a fibra de PET foi possível obter um concreto estrutural de acordo com a classe de agressividade I imposta pela NBR 6 I I 8 [8].

A diferença ocasionada pela adição de fibra pode ser justificada porque além de diminuir a trabalhabilidade no concreto, o PET apresentou-se no formato de fibra, que apresenta melhores resultados na resistência à tração do que quando analisada a resistência à compressão.

\subsection{Ensaio de Tração por Compressão Diametral}

Este ensaio foi feito de acordo com a NBR 7222 [9] e foi feito no laboratório de Materiais de Construção do Centro Universitário ITPAC com auxílio da prensa hidráulica EMIC 23-200. Os corpos de prova são submetidos a cargas constantes de compressão até a sua ruptura, utilizando-se da carga máxima aplicada, calcula-se a resistência a tração, através da Equação 3:

$$
F_{c t, s p}=\frac{2 x F}{\pi x d x l}
$$

Onde: $F_{c t, s p}$ é a resistência de tração por compressão diametral, em Mpa; F é a força máxima aplicada, em N; d é o diâmetro do corpo de prova, em mm e lé o comprimento do corpo de prova, em $\mathrm{mm}$. 
Tabela 4. Resultados do Ensaio de Tração por Compressão Diametral

\begin{tabular}{lllcc}
\hline & PET 0 & PET I & PET 2 & PET 3 \\
\hline Média (MPa) & 2,5 & 3,3 & 3,15 & 3,14 \\
Desvio Padrão (MPa) & 0,15 & 0,18 & 0,19 & 0,18 \\
Coef. de variação(\%) & 0,060 & 0,055 & 0,060 & 0,057 \\
\hline
\end{tabular}

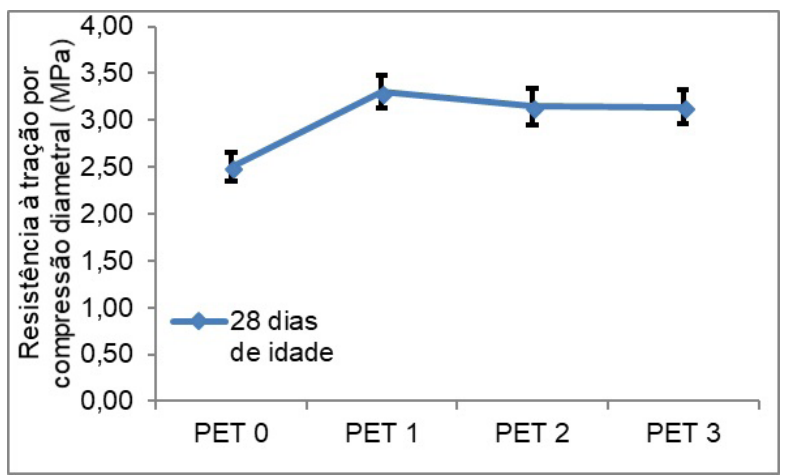

Figura 3. Resistência à tração por compressão diametral.

Os valores encontrados podem ser observados na Tabela 4.

Conforme analisado em tabela, houve um aumento da resistência à tração, demonstrado também na Figura 3, esse fator pode ser explicado pela característica da fibra de ser reforço e ponte de transferência para os esforços aplicados.

Além da resistência a tração, também foi perceptível que ao romper o corpo de prova não houve a ruptura global da peça, pois a fibra continuou atuando na ligação dos elementos, conforme se pode analisar na Figura 4:

\section{CONCLUSÃO}

Conforme apresentado, foi possível verificar, através deste estudo, os efeitos da incorporação de diferentes porcentagens de fibra de PET no concreto. Ademais, a produção deste compósito orientou a análise das melhorias na capacidade de deformação do mesmo e proporcionou uma correta destinação às embalagens de PET em desuso. Para avaliar o desempenho deste material, foram utilizados

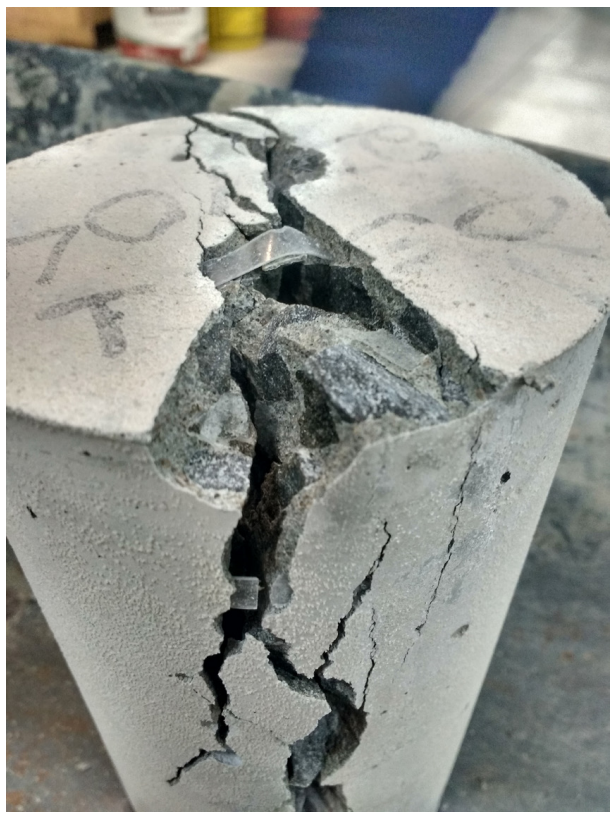

Figura 4. Corpo de prova após a ruptura na prensa.

alguns procedimentos de ensaios laboratoriais, dentre eles, ensaios de resistência mecânica. Os corpos de prova foram submetidos a tal análise através do ensaio de compressão axial e tração por compressão diametral.

Com o processo de adição de fibras de PET, o material teve ruptura global da peça, visivelmente, minimizado. Além disso, o desempenho de resistência à tração do concreto com fibras obteve um aumento em relação ao concreto sem fibras.

A incorporação da fibra não produziu valores tão significativos no quesito de resistência à compressão da peça, estes valores reduziram em detrimento do concreto referencial, contudo, foi possível obter-se um concreto estrutural de classe de agressividade I, de acordo com a NBR 6 I I 8 [8].

Outrossim, no estudo realizado verificou-se que os valores de resistência à compressão axial e à tração por compressão diametral do compósito desenvolvido nos três teores de fibra de PET (4,5; 5 e 5,5\%) não obtiveram grande divergência entre si, aos 28 dias de cura.

\section{REFERÊNCIAS}

I Claro, PBO; Claro, DP; Amâncio, R Entendendo o conceito de sustentabilidade nas organizações. Revista Administração. 2008;43(4):289-300.

2 Galvão J. Uso de materiais poliméricos reciclados em estruturas de concreto para superfícies hidráulicas. Curitiba, 2010.

3 Associação Brasileira de Normas Técnicas. NBR 7217. Agregados - Determinação da composição granulométrica. Rio de Janeiro: ABNT; 1987.

4 Associação Brasileira de Normas Técnicas. NBR 9776. Agregados - Determinação da massa específica Chapman. Rio de Janeiro: ABNT; 1987. 
5 Associação Brasileira de Normas Técnicas. NBR NM 45. Agregados - Determinação da massa unitária e do volume de vazios. Rio de Janeiro: ABNT; 2006.

6 Associação Brasileira de Normas Técnicas. NBR 5738. Concreto - Procedimento para moldagem e cura de corpos de prova. Rio de Janeiro: ABNT; 2015.

7 Associação Brasileira de Normas Técnicas. NBR 5739. Concreto - Ensaios de compressão de corpos-de-prova cilíndricos. Rio de Janeiro: ABNT; 2007.

8 Associação Brasileira de Normas Técnicas. NBR 6I I8. Projeto de estruturas de concreto - Procedimento. Rio de Janeiro: ABNT; 2014.

9 Associação Brasileira de Normas Técnicas. NBR 7222. Concreto e argamassa - Determinação da resistência à tração por compressão diametral de corpos de prova cilíndricos. Rio de Janeiro: ABNT; 201 I .

Recebido em: 20 Nov. 2017

Aceito em: 26 Jul. 2018 